\title{
Exploring the Traditional Farming Culture and Improving the Local Cultural Confidence: Solving the Problem of Rural Tourism Homogenization
}

\author{
Weina $\operatorname{Yan}^{1, *}$ \\ ${ }^{1}$ School of design, Leshan Normal University
}

\begin{abstract}
Since the rise of rural tourism in China in the 1980s, the natural conditions have mainly been relied on to develop such tourism projects as flower appreciation, fruit picking, fishing, and farm foods focusing on agricultural sightseeing and experiencing the rural life, which has long ignored the cultural attributes of rural tourism, resulting in the serious homogenization of rural tourism. The author believes that exploring traditional farming culture and improving local cultural self-confidence are the effective ways to solve the problem of rural tourism homogenization, to achieve the general requirements of agricultural and rural development in the report of the 19th National Congress of the Communist Party of China on 'industrial prosperity, ecological livability, rural civilization and affluent life', and to promote rural revitalization.
\end{abstract}

\section{Introduction}

According to the data disclosed by the website of the Ministry of Culture and Tourism, the number of domestic tourists in 2018 was 5.539 billion, and the total number of inbound tourists was 291 million, of which 4.119 billion were urban residents. The tourism cost of urban residents was CNY 4.26 trillion, and the direct and indirect employment of tourism was 79.91 million, accounting for $10.29 \%$ of the total employment population in China. In 2019 , the number of domestic tourists was 6.006 billion, the total number of inbound tourists was 0.3 billion, and the number of urban residents was 4.417 billion. The tourism cost of urban residents was CNY 4.75 trillion, and the direct and indirect employment of tourism was 79.87 million, accounting for $10.31 \%$ of the total employment population in China. In 2020, despite the impact of the Covid-19 pandemic, the number of domestic tourists was still 2.879 billion, among which 2.065 billion were urban residents. The tourism cost of urban residents was CNY 1.80 trillion, and each resident spent CNY 870.25 in average each time of travel. [1] Tourism occupies an important position in the domestic economic GDP, and urban residents have become an important force in promoting the rapid development of domestic tourism. With the take-off of China's economy, the upsurge of reviving traditional culture has become increasingly fierce. Feeling the context of the traditional culture and pursuing the root of the national culture have become the general demand of urban residents' tourism. Fang believes that people's tracing their daily life back to tradition, and on this basis, establishing the new 'lifestyle' of the Chinese people is actually a kind of cultural self-confidence of them and a recognition of their own national culture. ${ }^{[2]}$ Currently, there is a general lack of local atmosphere and local cultural heritage in the domestic tourism industry with a severe homogenization of tourism products. There is a certain gap between the current situation of rural development, mainly based on agricultural tourism, and the current urban residents' needs for local cultural tourism. The author believes that the key to solve this problem is to integrate all forces, fully explore the traditional farming culture and improve the confidence of local culture.

\section{Main Body}

Mr. Fei said, "As seeds and genetic factors are studied in biology, the seeds should also be studied in culture. We should study how to continue to keep the seeds, and how to maintain the health genes within the seeds." [3] The thought of timing, appropriateness, abidance and harmony, contained in farming culture, is the root of Chinese civilization, and the core of local cultural tourism lies in the retrospect of the farming culture. From another perspective, it is not only the internal demand of contemporary Chinese people to re-recognize and affirm the value of traditional culture and return to their own traditional culture, but also the internal motivation to stimulate the vitality and vigor of the Chinese traditional culture. For traditional culture is the core and soul of rural tourism, it is the endogenous cultural needs of rural tourism to explore the traditional farming culture with regional characteristics and to establish local cultural confidence from a historical height. 


\section{Exploring the Traditional Farming Culture and Constructing the Rural Tourism Intention}

Farming culture is the core of the local culture, and its simple philosophy of life is not only the link that rural society relies on to maintain, but also the main vein of the traditional Chinese culture. No matter how the times change, the farming culture is always the people's cultural gene deeply rooted in their blood. There is the ancient saying goes like this, 'The lost rites can still be found in the folk'. In the modern Chinese cities that were constructed on the basis of western industrial civilization, much traditional culture has disappeared, while in the vast rural areas, especially in the relatively underdeveloped areas, the local culture achieves the inheritance of farming culture to a relatively better degree. More and more people begin to realize that the development of future societies will not be merely limited to the style of western cities, neither will industrial civilization be the only excellent civilization. When urban residents re-recognize the great value of traditional culture, local culture will become the blueprint for people to pursue their own cultural genes and reshape their life prospects. It is both an opportunity for the strategy of rural revitalization and a challenge for the development of rural tourism. The author believes that in order to get rid of the domestic rural tourism model, mainly based on agricultural sightseeing, and to break the serious homogenization of rural tourism, the key to constructing cultural and compound rural tourism model is to explore the essence of traditional farming culture according to the unique conditions of the region, to put the local culture with regional characteristics in the central position of rural tourism development, and to realize 'the positive inheritance' and 'the all-round succession' of local culture. ${ }^{(1)}$ As the saying goes 'each place has its own way of supporting its own inhabitants', the key to breaking the current situation of homogenization is to build the rural tourism intention with the regional culture as the core feature and realize differentiated development.

As 'the most determined watcher of the Li culture in China', Wangxia Village of Hainan Province has built the Li cultural tourism areas, represented by in Poetry and Paintings - Sanpai Village, In Golden TimeHongshui Village, and in Wines and Songs - Langlun Village. With the combination of the experience of living in a boat house and the unique marriage customs, the festival celebrations, and the characteristic handicrafts of the Li nationality, the image of the rural tourism of the $\mathrm{Li}$ nationality is shaped from the cultural level, at the same time of realizing the differentiated development. With building 'an oriental international cittaslow' as its core aim, Nanjing's Yaxi International Cittaslow has been highlighting the 'slow' cultural image, achieving the differentiated development with its unique landscapes and tourism positioning. The northern part of Anshun City in Guizhou Province and the central and southern regions of Qiandongnan Prefecture, with its unique Miao culture as the core, have created a large number of tourism attractions of folk culture and ethnic villages, not only integrating Miao culture and Dong culture into forming the landscape culture of the blocks, but also realizing the combination of local culture and rural tourism with a strong atmosphere of national culture. By relying on stones, groups of stone buildings have been formed in the unique natural landscapes of Taihang Mountain by the rural tourism in ancient villages among Taihang Mountain in Hebei Province, such as Yujia Village and Daliangjiang Village of Jingxing County in Shijiazhuang City, Yuanqu Village and Dawa Village of Shexian County in Handan City, Wangnao Village of Xingtai County in Shahe City, Huangcha Village of Neiqiu County, Xiyanghe Village of Huailai County in Zhangiiakou City, Biancheng Village and Songjiazhuang Village in Yu County, Zhangjiakou City. Combined with the special local customs and the regional cultural atmosphere, the unique stone architectural landscape has formed the unique rural tourism characteristics and created the unique tourism intention. The Furong Ancient Town in Chengdu City of Sichuan Province has formed the unique regional cultural tourism intention by taking western Sichuan folk dwellings as a unique regional landscape, combining the unique Tianfu cuisine culture of Sichuan, taking advantage of the characteristic handicrafts represented by Sichuan embroideries, Sichuan brocades, sugar paintings and bamboo curtain paintings, and underlining the regional artistic performance represented by Sichuan Opera, Sichuan Pure Sound and Jinqian Allegro, and the characteristic teahouse culture, attracting the continuous flow of Chinese and foreign tourists to linger in this town.

China has a vast territory. The unique natural landscapes and climates in various regions have formed a vast range of different regional local culture. The local culture in any place has its own unique charm, which is the precious wealth of the development of rural tourism in China. The deep exploration of the local culture with regional characteristics, and the creation of the unique cultural image of rural tourism, combined with unique local conditions and customs as well as manners and folkways, is the cultural core to realize the characteristic development of rural tourism.

\section{Improving the Local Cultural Confidence and Reshaping the Rural Cultural Landscapes ${ }^{(2)}$}

The concept of a simple life and the thought of farming culture carried by local culture are the cultural genes of the continuation of Chinese civilization, and the scenes from village life have always been in the nostalgia of the Chinese nation. It can be said that among many cultural memories, local memory is the core one in the deepest part of the Chinese national spirit. Local memory is the skills of labor tools and the relatively stable rural customs gradually formed by the long-term labor and the life practice of the people in a certain area, and it is also 'the consensus knowledge' formed by human actors in the process of continuous social interaction. ${ }^{[4]}$ The local memory can produce a strong cultural centripetal force for the people with life experience in a specific area and become a place where wanderers away from their hometowns dream of and pine for. Due to the huge gap 
between the rural economy and the urban economy which results in a serious loss of rural labor, both the rural construction and the living standards are trying to catch up with the cities, no longer agreeing with local culture. This is also the root cause of the new rural construction's blindly pursuing urban standards. The author believes that the characteristic development of rural tourism should first improve the confidence of the local culture with regional characteristics as its core, enhance the cultural appeal and cohesion of rural life landscape, promote local culture into a new trend of Chinese people, improve the confidence of the local culture, and stimulate young people to return to their own hometowns to build them. In the second place, the cultural landscapes of village groups based on local memory should be created and the spiritual home should be formed to accommodate the concentrated nostalgia. The rural cultural landscape is both the material carrier of the local memory and the historical witness of the rural life, by carrying rich regional culture and special local conditions customs, and appropriate local cultural landscape can stimulate people's strong sense of cultural belonging and cultural identity.

The creation of local cultural landscapes is not to completely reproduce the real rural life in the past, nor is it to build a completely new building on a new land, but to carefully select the elements of the local landscapes on the basis of the original village with the local unique local culture as its main line, to look for the landscape image in line with a cultural main line, and to deduce a poetic landscape of rural life through the narrative design technique of landscapes ${ }^{3}$ with a kind of freehand brushwork between similarities and differences. The choices of the theme can be both the historical culture and the folk customs of the village, and can also be a unique natural landscape. Through the reasonable planning and layout, it can present the smooth experience of introduction, elucidation of the theme, transition to another viewpoint and summing up as well as the feeling of making a difference with one step in the sighting, and can make landscape elements a prop for tourists to experience the local culture. For example, Lishuiyanxia Village in Zhejiang Province took advantage of the historical inheritance and evolution of the Zhu family's story, the stone architectural style with a history of thousands of years and the reputation as 'the best stone village in regions south of the Yangtze River' to form a unique rural cultural landscape. The Taiping Ancient Town in Gulin County of Luzhou City in Sichuan Province was based on the history of how the Red Army stationed in Taiping Ancient Town to cross Chishui for four times, forming a narrative rural cultural landscape with red tourism as its main line, which is a typical case of shaping the rural cultural landscape.

In the location-context theory ${ }^{4}$, it is regarded that there is a relationship between the location form and the culture, while the location form is a specific manifestation of a certain cultural connotation. Different locations convey different cultural connotations, and individuals shall harbor a sense of attachment and belonging to specific locations. Zhan Yong, a member of the CPPCC in Jiangxi Province, pointed out that creating the carrier of the local memory based on the historical roots of traditional villages can provide strong support for activating local culture. [5] This means that the reconstruction of rural cultural landscapes should pay attention to constructing the connection between the regional culture and the local context, and focus on the inheritance and retention of the connotation of the regional culture and the local context, especially those religious culture and family culture with local characteristics. For example, when creating rural cultural landscapes, we should abide by the principle of repairing the old just as the old. We should not only retain the regional appearance, but also use traditional technology and local materials as well as craftsmen in choosing specific materials and craftmanship. The Taiping Ancient Town in Luzhou City of Sichuan Province adopted the bluestones and cobblestones, obtained by the local people from the Chishui River, to create a red block landscape, which wellmaintained the context of the local landscape.

\section{Building the Poetic Rural Tourism through the Multi-Subject Cooperation}

At present, China's rural tourism is mostly of the spontaneous nature by villagers. Due to its own limitations and deviation in its understanding of the local culture, there is the lack of culture value in either homestays or the design of tourism products, resulting in the tendency of serious homogenization, the reason for which is the lack of macro guidance and overall planning. It is by far not enough to build the beautiful countryside and create the poetic rural tourism only by villager' spontaneous behaviors, and it is necessary to form a co-construction model of multi-subject cooperation under the guidance of government and the lead of policies.

Firstly, it is important for the government to play the leading role in the development of rural tourism. Due to the short history of development in China's rural tourism, there are still some problems in the management of rural tourism by the government. For example, at the national level, it is the Department of Agricultural Economy of the National Development and Reform Commission, the Agricultural Products Processing Bureau of the National Agricultural Bureau and the Planning and Development Finance Department of the National Tourism Bureau that are responsible for the centralized management of the rural tourism. In 2018, the State Council reorganized the Ministry of Agriculture and Rural Affairs and the Ministry of Culture and Tourism. However, in the units of the provincial level, there began to appear the serious phenomenon of intersecting management, for example, the declaration and the management of the projects of rural tourism in Shanxi Province are attributed to different departments, Jiangxi Provincial Tourism Administration only manages the rural tourist attractions and the scenic spots that have been declared and approved, the demonstration sites of rural tourism or star-rated farmhouses in Meishan City of Sichuan Province are managed by the tourism bureau, while other aspects are managed by the agricultural sector, and the projects of rural tourism in Luoyang City of Henan Province are 
promoted by agricultural departments, while the publicity and the promotion are performed by tourism departments. At the township level, it should have been supposed to be the foothold of the management of rural tourism, but there exists the embarrassing situation that the local party committee secretaries in many regions even do not know which department should be responsible for the management of rural tourism. It can reflect the fact that at present in rural tourism management there is the confusion of responsibility and the mutual constraints in rural tourism management by all levels of governments from provinces to cities to counties and to villages. Judging from the development of rural tourism in many places, the practice of Zhejiang Province is a bright spot. The Agricultural Office of Zhejiang Province is mainly responsible for the construction of beautiful villages and customs towns, and the Tourism Commission focuses on rural tourism and homestays. The tourism and agriculture are directly managed by a deputy mayor, with an excellently coordinated work performance. Wang Xingbin, a tourism planning expert of the State Tourism Administration, believes that significant as the cooperation between the two major departments of the State Council is, how to set up the branches of rural tourism in provinces, cities, counties, towns and villages and how to divide their functions shall be more important. [6]

Secondly, it is important to shape the artistic rural lifestyle through multi-agent cooperation. Rural tourism in its final significance is to establish a new way of life in the original groups of rural settlements, and its natural subjects are the villagers, so the development of rural tourism should follow the principle of being based on the rural situation and making policies according to the specific village. On the one hand, it is necessary to fully protect the legitimate rights and reasonable interests of the villagers from the policies, and to fully mobilize the backbone of the local culture, namely, the cultural elite in the countryside ${ }^{[7]}$. They may be represented by the rural sages who have been living in the countryside, or may be the young people who go out to study or work and return to their hometowns after that. These people not only have deep rural cultural heritage, but also have the advantages of modern civilization, and hence they can become an indispensable force for the development of rural tourism. On the other hand, it is necessary to fully mobilize the enthusiasm of private capitals to invest in the development of rural tourism projects, deepen the understanding of private capitals on rural revitalization projects, and fully attract private capitals to join the development of rural tourism projects in the form of shares or sole proprietorship. The third aspect is to give full play to the role of universities and research institutes in serving localities to help rural revitalization. Domestic universities have begun to join the research and training programs of the inheritors of the intangible cultural heritage led by the Ministry of Culture since 2017. For example, 57 universities, such as Central Academy of Fine Arts, Guizhou University for Nationalities and Sichuan Academy of Fine Arts, have successively participated in nearly 200 times of research, studies and trainings. However, there is still great potential for universities and research institutes to help the rural revitalization of rural tourism development. In this regard, we can appropriately learn from some advantageous practices. For example, the Ministry of Education of Taiwan issued the curriculum standard of 'local teaching activities' in 1993 and promoted it in primary and secondary schools. Colleges and universities engaged in traditional art such as Fuxing Drama School, Guoguang Art School and Huagang Art School arranged related courses of 'understanding Taiwan' and 'national art activities'. In addition, the National Taiwan University of Arts not only has a 'traditional art research center', but also established a 'traditional art research institute', and trains professionals through such forms as opening classes for masters of national arts. ${ }^{[8]}$ Cornell University in the United States has set up special training courses and lectures for farmers and entrepreneurs in rural tourism-related industries to promote the innovation of business philosophy and provide talent guarantee for improving the quality of rural tourism and avoiding homogenization.

Government management and policy support is the root for establishing a government-led model of multiagent cooperation. Full play also should be given to the power of scientific research institutes and private capitals as the branches and leaves in rural tourism construction. In addition, the role of villages as flowers, especially the rural sages with knowledge, culture and local heritage, should be fully mobilized in the reconstruction of local culture. The healthy development of rural tourism can be guaranteed by reasonable distribution of the interests of each power, with a consistent pace and a tacit cooperation.

\section{The Conclusion and the Discussion}

With the increasing upsurge of the revival of traditional culture, rural tourism has grasped the opportunity to transform from the shallow sightseeing tourism to the deep cultural tourism. How to seize the opportunity to overcome the serious drawback of the homogenization in current rural tourism so as to achieve the differentiated, deepening and qualitied development in rural tourism is the focus of the industry. The author discusses the countermeasures to solve the problem of rural tourism homogenization from three aspects: constructing the tourism intention, reshaping the rural cultural landscape and co-building the poetic rural tourism. Although China's rural tourism industry started late, after decades of experience and exploration, there have been many excellent cases and experience worthy of promotion. Through these excellent cases, it is not difficult to find that high-quality rural tourism projects can be produced only by exploring the traditional culture with regional characteristics, improving the confidence of the local culture, promoting the multi-agent cooperation and coconstruction, and performing strong governmental promotion and policy guarantee. Compared with the successful practices of other countries and regions, there is still much room for improvement in China, especially in giving full play to the role of scientific research institutes in exploring traditional culture with regional characteristics and serving the construction of rural 
tourism projects. Full affirmation and utilization of rural sages and young people who go out to study or work and return to their villages shall be further expanded.

\section{Notes}

(1) 'The positive inheritance': It is necessary to inherit the traditional local culture and to create the new things to meet the needs of modern life. It is necessary to protect the original ecological local culture and create the new ecological local culture.

'The all-round succession': We should not only inherit 'the context' of local culture, but also selectively inherit 'the connection of people' as the carrier of local culture. We should not only inherit the material representation of local culture, but also pay attention to the spiritual connotation of local culture.

Zhang RJ. A Study on the Protection and Inheritance of Local Culture in the Process of New Urbanization. CoOperative Economy \& Science. 2021 Feb. 1; 10-12: 1672190X.

(2) Cultural landscapes: It was proposed by the American scholar Sauer in 1927, referring to the forms of human activities attached to the natural landscapes, which include both material and non-material cultural landscapes.

(3) The narrative design technique of landscapes: The narratology is applied to the design of rural landscapes. Through the landscape narrative, the local culture contained in the countryside is interpreted, and its relationship with landscape space, landscape elements and landscape structures is studied. Through the experience of scenario stories, the expression of local culture connotation in rural tourism is realized.

Chen YY, Chen ChH. A Research on the Narrative Design of Rural Cultural Landscapes from the Perspective of Rural Cultural Tourism. Modern Agriculture Research. 2021 Mar 4; 63-65: 2096-1073.

(4) 'The location-context theory': This abstract concept was first proposed by the famous American designer Kevin Lynch based on the research and conception of urban planning. The location-context theory believes that the elements such as the principles in construction, the nodes and the buildings in the city are interrelated and interdependent. The building space and location should pay attention to its relationship with the environment and the coordination between various architectural elements and regional context.

Lynch K. The Image of the City. Beijing: Huaxia Publishing House; 2001.

\section{The Project Supported by Funds}

Phased achievements of the key scientific research project of Leshan Normal University's discipline construction "development and research of lacquerware crafts with Sichuan Regional Characteristics" (No.: wzd042)

Address for sending the sample journal: 6 / F, unit 2, building 4, Edinburgh community, 1198 Binhe Road, Shizhong District, Leshan City, Sichuan Province

\section{References}

1. The Data are obtained from the website of Finance Department, Ministry of Culture and Tourism of China.

Available from: https://www.mct.gov.cn/

2. Fang LL. The Revival of Traditional Handicrafts and the Road of Ecological China. Folklore Studies. 2017 Nov. 15; 5-11+158: 1002-4360.

3. Fei XT. The Inheritance and Creation of Culture: The Complete Works of Fei Xiaotong (Vol. 14). Beijing: Qunyan Press; 2005. 31.

4. Chen Y. The Media Memory and the Image Expression of Local Archives. Journal of News Research. 2021 Feb. 10; 106-107: 1674-8883.

5. Zhan Y. Activating the Local Culture and Promoting the Local Civilization. jxnews. 2021 Mar: Sect. Advice on Administration: 02.

6. Wang XB. Institutional Reform of the State Council and Institutional Innovation of the Rural Tourism. China Economic Net. 2018 Apr. 5.

7. Zhang RJ. A Research on the Protection and Inheritance of Local Culture in the Process of New Urbanization. Co-Operative Economy \& Science. 2021 Feb. 1; 10-12: 1672-190X.

8. Yuan L, Gu J. Intangible Cultural Heritage Studies. Beijing: Higher Education Press; 2012 Aug. 19-23. 